\title{
Treatment of open tibia fractures in Sub-Saharan African countries : a systematic review
}

\author{
Kouamé Jean-Eric Kouassi, Julie Manon, Loïc Fonkoue, Christine Detrembleur, Olivier Cornu \\ From the Experimental and Clinical Research Institute (IREC), Neuro-Musculo-Skeletal Pole (NMSK), \\ Université catholique de Louvain, Brussels, Belgium
}

Open tibia fracture (OTF) treatment is well documented in developed countries. Yet, this fracture pattern remains challenging because it is associated with an increased risk of infection and delayed union, particularly in case of Gustilo III B and C open fractures. Since access to healthcare is limited in SubSaharan African countries, this paper explores the results of OTF management in this setting.

A systematic review of the literature was conducted using current databases such as MEDLINE, Cochrane, EMBASE, PubMed, ScienceDirect, Scopus, and Google Scholar in order to identify prospective studies with cohorts of patients treated for OTF. Studies were included based on predefined inclusion and exclusion criteria. The quality of studies was analyzed by the Coleman Methodology Score (CMS).

Eight papers met the inclusion criteria and had an average CMS of 70 (range 54-73). The most common treatment was non-operative management of the fracture with cast immobilization (67\%). Gustilo Type II and III fractures were associated with a higher risk of complications. The infection rate was $30 \%$. Malunion, chronic osteomyelitis and nonunion were observed in $14.5 \%, 12.3 \%$, and $7 \%$ of the cases, respectively. More complications were observed with non-operative treatment (cast immobilization) than with surgical fixation.

Although the surgical environment does not allow for internal fixation, poor results of non-operative management of open fractures should lead to the introduction of trainings on the proper use of external fixators. It is also advisable to support the development of locally produced external devices that utilize local

All authors declare that they have not received any funding or other benefits in support of this study. No relevant financial relationships to disclose. source materials, which would make external fixation available at a reasonable cost.

Keywords : Africa ; cast immobilization ; developing countries; open fracture; tibia.

\section{INTRODUCTION}

Open tibia fracture (OTF) treatment is well documented in developed countries and the management principles of open fractures are well established (1). Yet, this fracture pattern remains challenging, as it is associated with an increased risk

Kouamé Jean-Eric Kouassi' (MD)

- Julie Manon ${ }^{1}$ (MD)

- Loïc Fonkoue ${ }^{1}(\mathrm{MD}, \mathrm{PhD})$

- Christine Detrembleur ${ }^{1}(\mathrm{PhD})$

- Olivier Cornu ${ }^{1,2}(\mathrm{MD}, \mathrm{PhD})$

${ }^{1}$ Experimental and Clinical Research Institute (IREC), Neuro-Musculo-Skeletal Pole (NMSK), Université catholique de Louvain, Tour Pasteur $+4,53$ avenue Emmanuel Mounier, 1200 Brussels, Belgium.

${ }^{2}$ Department of Orthopedics and Trauma, Cliniques universitaires Saint-Luc, Université catholique de Louvain, Avenue Hippocrate 10, 1200 Brussels, Belgium.

Correspondence : Kouamé Jean-Eric Kouassi, Unité de recherche NMSK - IREC Université catholique de Louvain, Tour Pasteur $+4-53$ avenue Emmanuel Mounier, 1200 Bruxelles, Belgium. Phone : 0032466354075, Fax : +32 2 7648904.

Email : medericko@yahoo.fr

- 2021, Acta Orthopædica Belgica. 
of infection and delayed union, particularly in case of Gustilo III B and C open fractures (2-4). Since poor urban populations in Sub-Saharan African countries have limited access to healthcare (5), the difficulties of treatment are multifactorial. Patients experience delays in surgical management that are related to their socioeconomic conditions and the absence of an efficient system to transfer the wounded to hospitals. Limited technical plateaus, lacking fixation hardware, and insufficient training in softtissue reconstruction techniques are also frequently reported $(5-8)$. We therefore wish to examine the results of OTF management in this setting by performing a literature review. The aims of this systematic review were 1) to assess the published literature on OTF in Sub-Saharan African countries, 2) to identify management strategies that have been applied, and 3) to evaluate the complication rate of these fracture stabilization methods. Poorer results were expected as compared to those observed in developed countries.

\section{MATERIALS AND METHODS}

The systematic review protocol complied with the guidelines provided by the Preferred Reporting

Table 1 - Criteria used to compute the Coleman Methodology Score for studies reporting the outcomes of open tibial fractures

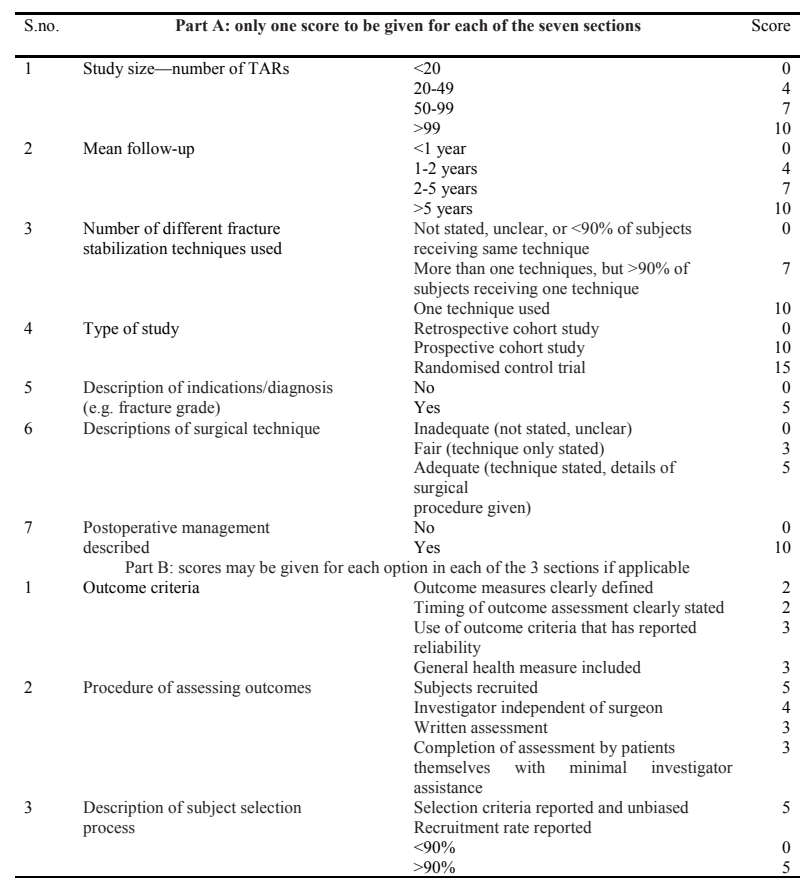

Items for Systematic Review and Meta-Analyses (PRISMA) statement (9). Literature search Keywords were identified using the PICO method in relation to the population (open tibial fracture OR developing countries OR Africa), the intervention (external fixators OR nails OR plaster of Paris), and outcomes (union OR malunion, OR, nonunion OR infection). The search was performed on articles dated between 2000 and October 2019, using several electronic databases: PubMed, Google Scholar, ScienceDirect, EMBASE, Scopus, the Cochrane Library, and additional African Journals. All references were exported from the databases to Endnote.

We selected available studies that were conducted in Sub-Saharan African countries. Articles meeting the following criteria were included: the reported language was English or French, the study was prospective, the study investigated populations of at least 20 patients, demographic data was included and the well-described treatment regimen was available, the Gustilo-Anderson classification was used (10), methods of fracture stabilization were identified, union and complications were described. Articles were excluded if they did not meet the above inclusion criteria, if they related to a neglected OTF, or if the study was retrospective or a case report. Two researchers (KE, CD) independently screened the titles and abstracts of the retrieved studies to assess eligibility, after duplicates were removed. Articles that met the inclusion criteria were selected for a full-text lecture, and corresponding authors were contacted when the full text was not available. Articles that met the inclusion criteria were also included for qualitative synthesis. Disagreements were resolved through consensus

Two authors independently scored the quality of the studies using the Coleman Methodology Score (CMS) $(11,12)$, which was adapted (Table 1) to evaluate studies reporting on OTF. The CMS is a method of analyzing the quality of studies being reviewed by assessing the methodology using 10 criteria, giving a total score between 0 and 100 . A score approaching 100 indicates that the study has a robust design and largely avoids chance, various biases, or confounding factors. A score $>85$ is considered excellent, $70-84$ is good, 50-69 is 


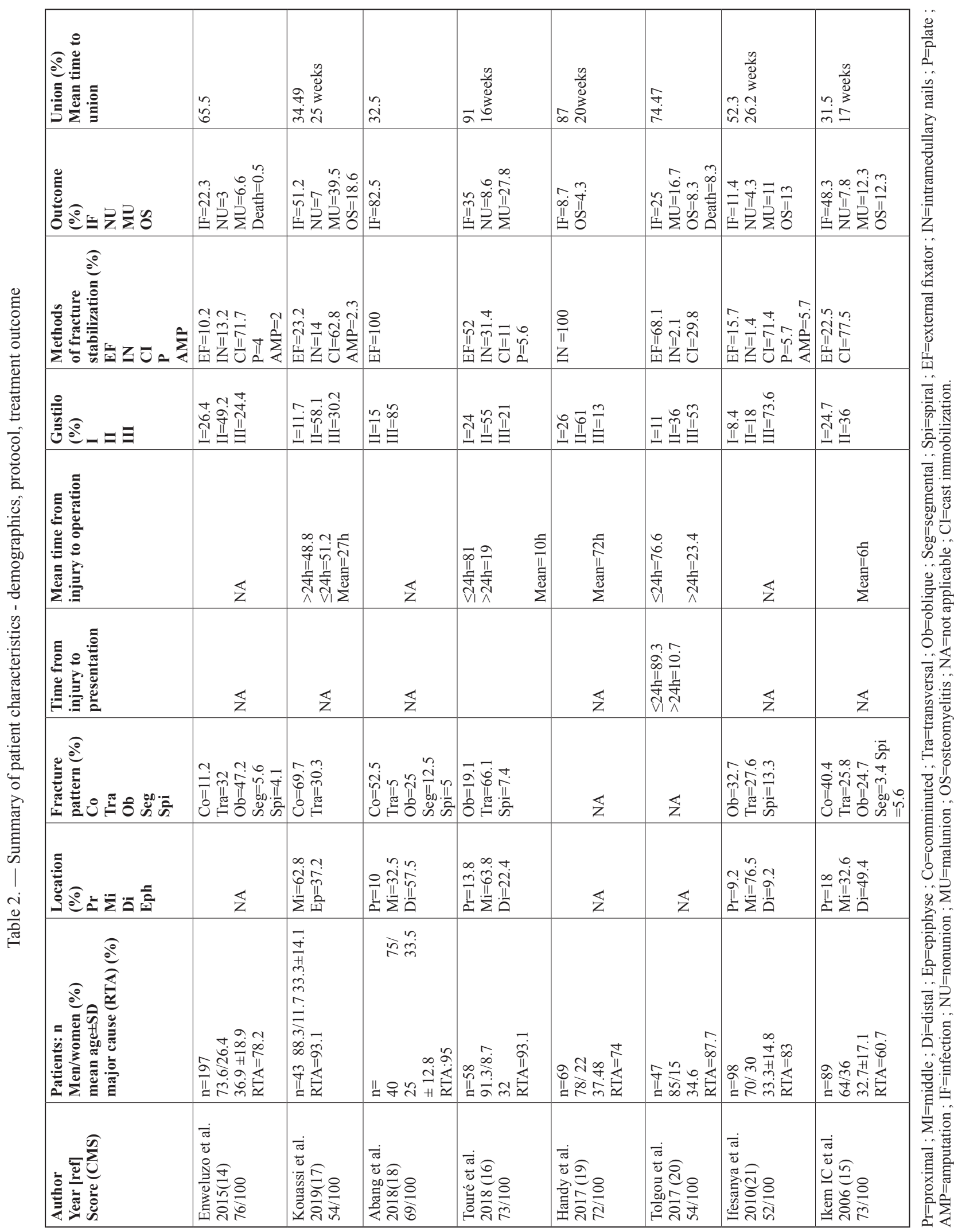


moderate, and $<50$ is poor. The CMS's subsections are based on the subsections of the Consolidated Standards of Reporting Trials (CONSORT) statement (for randomized, controlled trials) (13).

Two authors (KE, CD) extracted data using a pre-pilot standardized form (Table 2), which included the first author's last name, publication year, CMS number, demographic data, diagnosis (fracture pattern), the Gustilo grade of the open fracture, interventions, and any complications (infection, malunion, nonunion). Statistical analysis was performed using SigmaPlot version 13. We calculated the median and quartile [25-75] of the outcomes. The risk of developing a complication was also determined according to the stabilization method and the Gustilo type of open fracture.

\section{RESULTS}

The electronic search yielded 2,651 articles, but only eight met the inclusion criteria and were considered eligible for the study (Fig. 1). The average CMS was 70.5 (range 54-73), which is indicative of good methodological quality (11). The eight studies (14-21) reported on 641 patients who were treated for an OTF. Their mean age was 34 years (range 33-36), with $77 \%$ males. The mechanism of injury was road traffic accident (RTA) in $85.3 \%$ (14-21). Fractures were predominantly in the middle third $(62.8 \%)$, followed by the distal third $(36 \%)(15-18,21)$. The comminuted fracture pattern was the most frequent (46.4\%), followed by transverse $(28.9 \%)$ and oblique fractures (25\%) (14-18,21). Gustilo II and III fractures accounted for $42.6 \%$ and $30.2 \%$ of cases, respectively. Regarding the time from injury to operation, $76.6 \%$ of patients were operated on within 24 hours $(16,17,20)$. Open wound management was described in all studies, but numerical data was only available in four studies $(15,16,20,21)$. Skin grafting was used in $44.07 \%$, primary closure in $21.3 \%$, and flap coverage in only $8.5 \%$. Secondary healing was expected in $10.8 \%$. Several techniques were used for fracture stabilization in seven studies (14-17,20,21), while one reported only external fixators (ExFx) (18) and another exclusively intramedullary nailing (19). Cast immobilization (CI) was solely used for fracture fixation in $67.1 \%$ of cases (Fig. 2). Primary

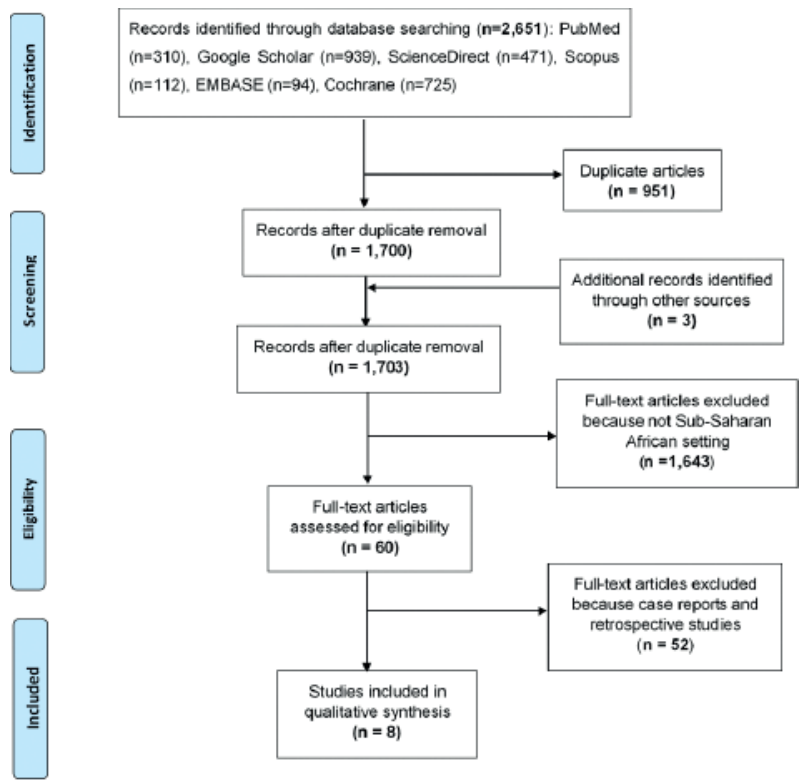

Fig. 1. - Flowchart of studies inclusion.

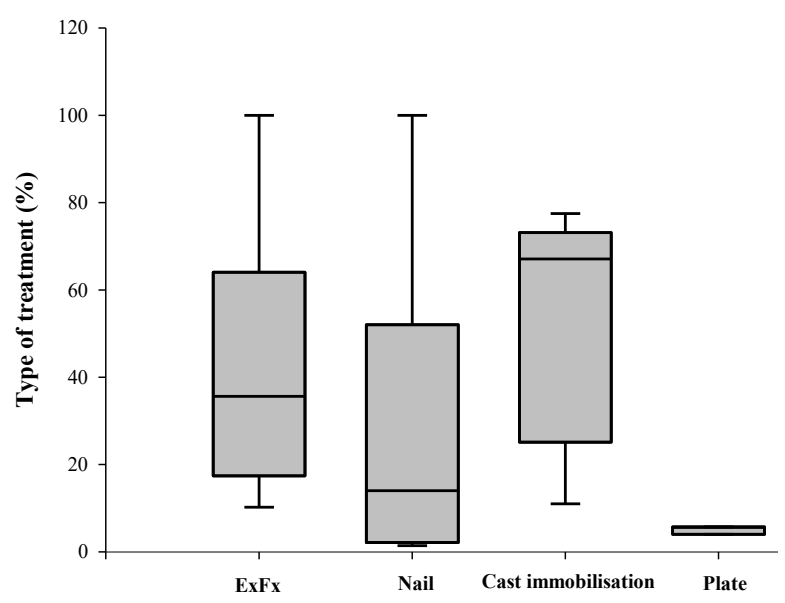

ExFx : external fixator

Fig. 2. - Box plot of Methods fracture stabilisation distribution.

amputation was performed in $7.7 \%$ of patients $(14,21)$ and secondary amputation was performed in $2.3 \%$ of patients (17). Fracture healing was reported after a mean delay of $20.6 \pm 4.4$ weeks. The union rate was $58.9 \%$ (14-21). (Fig. 3) summarizes the pooled data regarding complication rates. Infections were frequent (30\%), and non-operative treatment/ CI was associated with an increased complication rate when compared to surgical fixation (Fig. 4). 


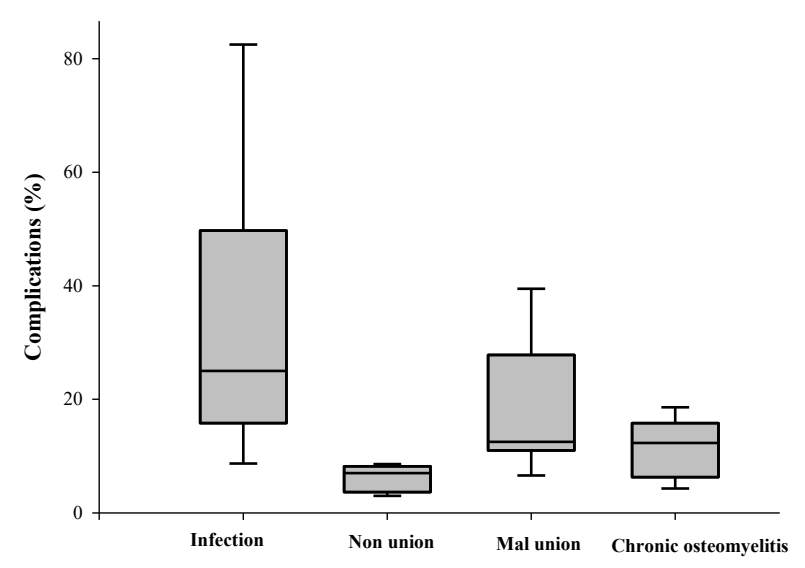

Fig. 3. - Box plot of complications rate distribution.

\section{DISCUSSION}

OTF management is a significant cause for concern in developing countries (22). OTFs are usually associated with a high complication rate (23), particularly infection, malunion, and nonunion (24). With regards to the complications observed, the average incidence of infections was $30 \%$. This overall infection rate is higher than the rates reported in some studies (25-27), but similar to others $(23,28-30)$. The high proportion of Gustilo III fractures in this series may explain the poorer results, although a systematic review of open Gustilo III B and C fractures reported lower infection rates (4). Better results might be expected in middle-income (25) or developed countries (31). Delayed treatment has been proposed as a potential cause of infection. However, Reuss and Cole reported that delayed operative management of up to 48 hours did not adversely affect infection rates (32). The timing for soft-tissue coverage is also controversial, as some advocate early flap coverage (33) and others advocate delayed wound closure (34). It has been observed that flap coverage within 72 hours reduced infection rates (3), and, for Gustilo III B fractures, soft-tissue coverage within (versus after) one week resulted in lower rates of infection $(8 \%$ versus $59 \%$ ) (35). It is not possible to confirm that the choice of secondary soft-tissue healing in our review negatively influenced the result. The average incidence of nonunion was lower than the rates reported in some studies $(28,31)$. With regards

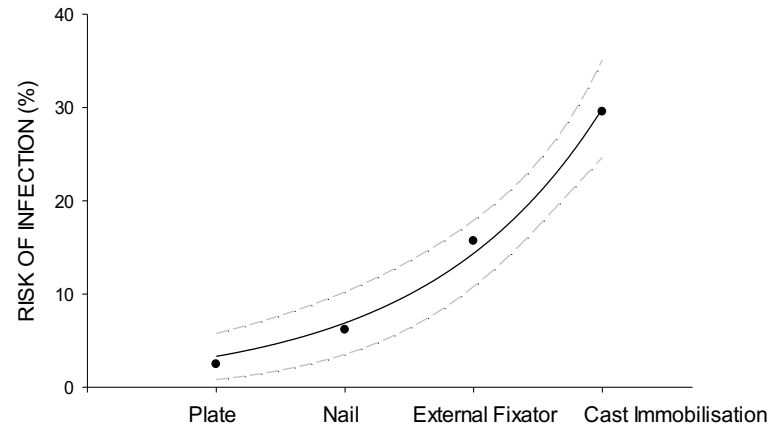

Fig. 4. - The trend curve for complications / restraint methods.

to malunion, the average incidence was higher than the rates reported in the existing literature (36). The predominant use of CI in place of modern surgical fixation in our series could explain these outcomes. However, the results are not fully comparable, due to differences in the methods used for fracture stabilization. Early stabilization is of paramount importance and, ideally, should be performed at the time of the initial debridement. This restores limb alignment, eliminates gross movement at the fracture site, limits further soft-tissue damage, and decreases the risk of further bacterial spread (37). The types of fixation currently available are ExFx, plates and screws, reamed and unreamed locking nails, and CI (38-40). However, specific problems are inherent to each treatment method, which means every method is less than ideal (24). Methods of fracture stabilization varied between studies. The CI was the most used because it is cheap, readily available and non-invasive (15,41). Access to the wound unfortunately remains difficult for inspection and dressing. Windows made on the CI often weaken it and compromise adequate maintenance of fracture reduction (15). Prolonged CI application caused joint stiffness, quadricep wasting, and secondary fracture 
displacement $(15,40)$. The potential advantages of ExFx include minimal soft-tissue stripping, as well as easy and quick application in emergency situations (42). The disadvantages, however, include track problems with the pins, reduction loss, and the potential for fracture from the pin track site $(24,43)$. The potential advantages of intramedullary nailing include improved cosmesis, early mobilization, and stable reduction (15). Its disadvantages include the potential for deep infection (osteomyelitis) and the spread of infection through the medullary canal (44). Postoperative infection rates are a major indicator of the viability of a particular surgical modality. In this series, the rates of infections and postoperative complications were higher with the use of plaster as a method of immobilizing fractures. This outcome was similar to that found in other studies $(17,20)$. We believe that, in Sub-Saharan African countries, economic constraints favor $\mathrm{CI}$ as a method of treatment for these fractures. $\mathrm{CI}$ is cheaper than $\mathrm{ExFx}$ or an intramedullary nail and removes any need for special instrumentation or intraoperative image intensifiers. We believe that local development of a low-cost ExFx (43) could provide an alternative to $\mathrm{CI}$ and ExFx devices that are available in developing country markets, since ExFx continues to be an acceptable modality of management in developing countries, where patients arrive late to hospitals and where local medical facilities are poorly available (15). ExFx is technically less demanding and requires no specialized equipment $(15,22)$. Although initial union rates may be lower with external fixation compared to intramedullary nailing, these fractures ultimately unite, even if the union time is prolonged (45). Finally, applying an ExFx to the initial injury may also decrease the ultimate rate of infections and osteomyelitis, which is considerably more debilitating and morbid than the trauma of repeat surgery that is secondary to a nonunion.

Some differences can be noted in the eight studies selected, which makes it difficult to compare and generalize results. First, the inclusion criteria were not the same. Second, the therapeutic attitude was not standardized because the methods of restraint were varied. Finally, details of antibiotic administration were not well described in most of the studies. However, this study does present a prospective collection of surgical data and, where possible, reveals how this data compares favorably to other studies in the literature. Despite the limitations of our study, we recommend the local development of a new, low-cost ExFx. We also recommend promoting trainings on the proper use of techniques for early and adequate soft-tissue coverage by orthopedic surgeons. Additionally, we propose employing a score that measures quality of life with good psychometric properties, such as SF-36 (46) or the lower extremity functional scale (LEFS) (47).

\section{CONCLUSION}

This review reveals that OTFs mainly concern young male subjects. The main cause is RTAs involving motorcycles. Fractures were essentially comminuted, and CI was mostly used as the method for fracture stabilization. The treatment of OTFs in this setting was associated with a high rate of complications, particularly when the fracture was managed non-operatively with CI. New low-cost ExFx implant designs and adequate soft-tissue cover (muscle flaps) could help improve treatment of OTFs in developing African countries.

\section{REFERENCES}

1. Hampton OP, Jr. Basic principles in management of open fractures. JAMA 1955 ; 159(5) : 417-419.

2. Gustilo RB, Mendoza RM, Williams DN. Problems in the management of type III (severe) open fractures : a new classification of type III open fractures. J. Trauma 1984 ; 24(8) : 742-746.

3. Singh A, Jiong Hao JT, Wei DT, Liang CW, Murphy D, Thambiah J, et al. Gustilo IIIB Open Tibial Fractures: An Analysis of Infection and Nonunion Rates. Indian J. Orthopaedics 2018 ; 52(4) : 406-410.

4. Saddawi-Konefka D, Kim HM, Chung KC. A systematic review of outcomes and complications of reconstruction and amputation for type IIIB and IIIC fractures of the tibia. Plast. Reconstr. Surg. 2008 ; 122(6) : 1796-1805.

5. Mathieu L, Mottier F, Bertani A, Danis J, Rongiéras F, Chauvin F. Management of neglected open extremity fractures in low-resource settings: Experience of the French Army Medical Service in Chad. Orthop. Traumatol. Surg. Res. 2014 ; 100(7) : 815-820.

6. Dada AA, Yinusa W, Giwa SO. Review of the practice of traditional bone setting in Nigeria. Afr. Health Sci. 2011 ; $11(2): 262-265$. 
7. Ikem IC, Oginni LM, Bamgboye EA. Open fractures of the lower limb in Nigeria. Int. Orthop. $2001 ; 25(6): 386-$ 388.

8. Museru LM, McHaro CN. The dilemma of fracture treatment in developing countries. Int. Orthop. 2002 ; 26(6) : 324-327.

9. Moher D, Liberati A, Tetzlaff J, Altman DG. Preferred reporting items for systematic reviews and meta-analyses : the PRISMA statement. PLoS Med. 2009 ; 6(7) : e1000097. https://doi.org/10.1371/journal.pmed.1000097

10. Gustilo RB, Merkow RL, Templeman D. The management of open fractures. J. Bone Joint Surg. Am. 1990 ; 72(2) : 299-304.

11. Coleman BD, Khan KM, Maffulli N, Cook JL, Wark JD. Studies of surgical outcome after patellar tendinopathy: clinical significance of methodological deficiencies and guidelines for future studies. Victorian Institute of Sport Tendon Study Group. Scand. J. Med. Sci. Sports 2000 ; 10(1) : 2-11.

12. Tallon C, Coleman BD, Khan KM, Maffulli N. Outcome of surgery for chronic Achilles tendinopathy. A critical review. Am. J. Sports Med. 2001 ; 29(3) : 315-320.

13. Moher D, Schulz KF, Altman DG. The CONSORT statement: revised recommendations for improving the quality of reports of parallel group randomized trials. BMC Med. Res. Methodol. 2001; 1: 2. https://doi. org/10.1186/1471-2288-1-2

14. Enweluzo G, Adekoya-Cole T, Mofikoya B, Giwa S, Badmus OJE, Surgery CAJo. Morbidity of Open Tibia Fractures in Lagos, Nigeria. East Cent. Afr. J. Surg. 2015 ; $20(2): 37-43$.

15. Kouassi KJ-E, Manon J, Fonkoue L, Kodo M, Detrembleur C, Cornu O. La prise en charge des fractures ouvertes de jambe dans une structure hospitalière en Côte d'Ivoire pose-t-elle problème et pourquoi? Rev. Chir. Orthop. Traumatol. $2019 ; 105(5)$ : 654-658.

16. Abang IE, et al. Early Outcome of Treatment of Open Tibial Shaft Fractures Using External Fixators in ResourcePoor Setting. Recent Adv. Biol. Med. 2018 ; 4(2018) : 1-9.

17. Touré L, Diallo M, Traoré T, Sidibé O, Dembélé M, Hans-Moevi A. Traitement des fractures ouvertes de jambe dans un hôpital de seconde référence. J. Afr. Orthop. Traumato. $2018 ; 3(1): 8-14$.

18. Handy ED SK, Bang GA, Touré S, Jean Emile B, Ngo Nong B, Agoh S. Ostéosynthèses par enclouage centromédullaire dans les fractures ouvertes de jambe vues tardivement: Procédure, Résultats et indications. Rev. Int. Sc. Med. 2017 ; 19(3) : 206-211.

19. Tolgou Y OA, Holdbrook-smith H. Treatment outcome of open tibial shaft fractures in a teaching hospital in Ghana. Postgrad. Med. J. Ghana 2017(6) : 47-53.

20. Ifesanya A, Omololu A, Ogunlade S, Alonge T. The burden of open fractures of the tibia in a developing economy. Nig. J. Plast. Surg. $2010 ; 6$ : 32-39.

21. Ikem I, Oginni L, Ogunlusi JJ. Determinants of management outcome in open tibia fractures in ile-ife. Niger J. Surg. Res. 2006 ; 8(1) : 81-83.
22. Mathieu L, Potier L, Ndiaye R, Mbaye E, Sene M, Faye M, et al. Management of Gustilo type IIIB open tibial shaft fractures with limited resources : experience from an African trauma center. Eur. J. Trauma Emerg. S. 2021 ; 47 : 217-223. 10.1007/s00068-019-01223-0

23. Lua J, Tan VH, Sivasubramanian H, Kwek E. Complications of Open Tibial Fracture Management : Risk Factors and Treatment. Malays Orthop. J. 2017 ; 11(1) : 1822.

24. Bali K, Aggarwal S, Kumar V, Mootha AK, Rawall S, Tahasildar N, et al. Operative management of type II and type IIIa open tibial fractures presenting from 6-24 hours after injury: an Indian experience. Curr. Orthop. Pract. $2011 ; 22(3)$ : 262-266.

25. Schade AT, Hind J, Khatri C, Metcalfe AJ, Harrison WJ. Systematic review of patient reported outcomes from open tibia fractures in low and middle income countries. Injury $2020 ; 51(2)$ : 142-146.

26. Kamat AS. Infection rates in open fractures of the tibia : is the 6-hour rule fact or fiction? Adv. Orthop. $2011 ; 2011$ : 943495.doi: 10.4061/2011/943495

27. Alhammoud A, Maaz B, Alhaneedi GA, Alnouri M. External fixation for primary and definitive management of open long bone fractures : the Syrian war experience. Int. Orthop. 2019 ; 43(12) : 2661-2670.

28. Yusof NM, Khalid KA, Zulkifly AH, Zakaria Z, Amin MA, Awang MS, et al. Factors associated with the outcome of open tibial fractures. Malays J. Med. Sci. 2013 ; 20(5) : 47-53.

29. Khatod M, Botte MJ, Hoyt DB, Meyer RS, Smith JM, Akeson WH. Outcomes in open tibia fractures: relationship between delay in treatment and infection. $J$. Trauma. $2003 ; 55(5)$ : 949-954.

30. Chua W, Murphy D, Siow W, Kagda F, Thambiah J. Epidemiological analysis of outcomes in 323 open tibial diaphyseal fractures : a nine-year experience. Singapore Med. J. $2012 ; 53(6)$ : 385-389.

31. Young S, Lie SA, Hallan G, Zirkle LG, Engesæter LB, Havelin LI. Risk factors for infection after 46,113 intramedullary nail operations in low- and middle-income countries. World J. Surg. 2013 ; 37(2) : 349-355.

32. Reuss BL, Cole JD. Effect of delayed treatment on open tibial shaft fractures. Am. J. Orthop. 2007 ; 36(4) : 215-220.

33. Naique SB, Pearse M, Nanchahal J. Management of severe open tibial fractures: the need for combined orthopaedic and plastic surgical treatment in specialist centres. J. Bone Joint Surg. British 2006 ; 88(3) : 351-357.

34. Russell GG, Henderson R, Arnett G. Primary or delayed closure for open tibial fractures. J. Bone Joint Surg. British $1990 ; 72(1): 125-128$.

35. Caudle RJ, Stern PJ. Severe open fractures of the tibia. $J$. Bone Joint Surg. Am. 1987 ; 69(6) : 801-807.

36. Milenković S, Mitković MJAfmN. External Fixation of Extra-Articular Open Tibial Fractures. Acta Fac. Medicae Naissensis 2018 ; 35(4) : 330-336.

37. Worlock P, Slack R, Harvey L, Mawhinney R. The prevention of infection in open fractures : an experimental 
study of the effect of fracture stability. Injury $1994 ; 25(1)$ : 31-38.

38. Keating JF, Blachut PA, O’Brien PJ, Court-Brown CM. Reamed nailing of Gustilo grade-IIIB tibial fractures. $J$. Bone Joint Surgery British 2000 ; 82(8) : 1113-1116.

39. Giannoudis PV, Papakostidis C, Roberts C. A review of the management of open fractures of the tibia and femur. $J$. Bone Joint Surg British 2006 ; 88(3) : 281-289.

40. Toivanen JA, Honkonen SE, Koivisto AM, Järvinen MJ. Treatment of low-energy tibial shaft fractures : plaster cast compared with intramedullary nailing. Int. Orthop. 2001 ; 25(2) : 110-113.

41. Twagirayezu E, Dushimiyimana J, Bonane AJE, Surgery CAJo. Open fractures I Rwanda: the Kigali experience. East Cent. Afr. J. Surg. 2008 ; 13(1) : 77-84.

42. Sellei RM, Kobbe P, Dienstknecht T, Lichte P, Pfeifer R, Behrens M, et al. Biomechanical properties of different external fixator frame configurations. Eur. J. Trauma Emerg. Surg. 2015 ; 41(3) : 313-318.
43. Hao ZC, Xia Y, Xia DM, Zhang YT, Xu SG. Treatment of open tibial diaphyseal fractures by external fixation combined with limited internal fixation versus simple external fixation: a retrospective cohort study. $B M C$ Musculoskelet Disord. 2019 ; 20(1) : 311 : 1-8. https://doi. org/10.1186/s12891-019-2679-9

44. Hofmann A, Dietz SO, Pairon P, Rommens PM. The role of intramedullary nailing in treatment of open fractures. Eur. J. Trauma Emerg. Surg. 2015 ; 41(1) : 39-47.

45. Alberts KA, Loohagen G, Einarsdottir H. Open tibial fractures : faster union after unreamed nailing than external fixation. Injury $1999 ; 30(8)$ : 519-523.

46. Bullinger M. German translation and psychometric testing of the SF-36 Health Survey: preliminary results from the IQOLA Project. International Quality of Life Assessment. Soc. Sci. Med. 1995 ; 41(10) : 1359-1366.

47. Mehta SP, Fulton A, Quach C, Thistle M, Toledo C, Evans NA. Measurement Properties of the Lower Extremity Functional Scale : A Systematic Review. J. Orthop. Sports Phys. Ther. 2016 ; 46(3) : 200-216. 